\title{
Solution Structure of Human Prolactin
}

\section{Kaare Teilum ${ }^{1}$, Jeffrey C. Hoch ${ }^{2}$, Vincent Goffin ${ }^{3,4}$, Sandrina Kinet ${ }^{4}$ Joseph A. Martial ${ }^{4}$ and Birthe B. Kragelund ${ }^{1 *}$}

${ }^{1}$ Department of Protein Chemistry, Institute of Molecular Biology and Physiology, University of Copenhagen, Øster

Farimagsgade 2A, DK-1353 Copenhagen $K$, Denmark

${ }^{2}$ Department of Molecular Microbial and Structural Biology, University of Connecticut Health Center Farmington CT 06030-3305 USA

${ }^{3}$ Université Paris Descartes Faculté de Médecine; INSERM U584, site Necker, 156 rue de Vaugirard Paris 75015, France

${ }^{4}$ Laboratoire de Biologie Moléculaire et de Génie Génétique, CBIG (Centre of Biomedical Integrative Genoproteomics), Université de Liège, B-4000 Liège, Belgium

${ }^{*}$ Corresponding author
We report the solution structure of human prolactin determined by NMR spectroscopy. Our result is a significant improvement over a previous structure in terms of number and distribution of distance restraints, regularity of secondary structure, and potential energy. More significantly, the structure is sufficiently different that it leads to different conclusions regarding the mechanism of receptor activation and initiation of signal transduction. Here, we compare the structure of unbound prolactin to structures of both the homologue ovine placental lactogen and growth hormone. The structures of unbound and receptor bound prolactin/ placental lactogen are similar and no noteworthy structural changes occur upon receptor binding. The observation of enhanced binding at the second receptor site when the first site is occupied has been widely interpreted to indicate conformational change induced by binding the first receptor. However, our results indicate that this enhanced binding at the second site could be due to receptor-receptor interactions or some other free energy sources rather than conformational change in the hormone. Titration of human prolactin with the extracellular domain of the human prolactin receptor was followed by NMR, gel filtration and electrophoresis. Both binary and ternary hormone-receptor complexes are clearly detectable by gel filtration and electrophoresis. The binary complex is not observable by NMR, possibly due to a dynamic equilibrium in intermediate exchange within the complex. The ternary complex of one hormone molecule bound to two receptor molecules is on the contrary readily detectable by NMR. This is in stark contrast to the widely held view that the ternary prolactinreceptor complex is only transiently formed. Thus, our results lead to improved understanding of the prolactin-prolactin receptor interaction.

(C) 2005 Elsevier Ltd. All rights reserved.

Keywords: NMR; cytokine; receptor interactions; four-helix bundle; hormone
Present addresses: K. Teilum, Department of Biophysical Chemistry, Lund University, SE-22100 Lund, Sweden; S. Kinet, Institut de Génétique Moléculaire de Montpellier CNRS UMR 5535/IFR 12234293 Montpellier Cedex 5, France.

Abbreviations used: hPRL, human prolactin; PRLR, prolactin receptor; GHR, growth hormone receptor; NOE, nuclear Overhauser enhancement; NOESY, NOE spectroscopy; HSQC, heteronuclear single quantum coherence; TOCSY, total correlated spectroscopy; PL, placental lactogen; RDC, residual dipolar coupling; ECD, extracellular domain; oPL, ovine placental lactogen; PDB, Protein Data Bank; RMSD, root-mean-square deviation; TROSY, transverse relaxation optimized spectroscopy.

E-mail address of the corresponding author: bbk@apk.molbio.ku.dk

\section{Introduction}

Prolactin (PRL) is a $23 \mathrm{kDa}$ four- $\alpha$-helix bundle protein hormone secreted by the anterior pituitary gland. More than 300 different biological functions have been attributed to PRL, ${ }_{1}^{1}$ the major ones being induction of differentiation and growth in mammary epithelia and stimulation of milk protein secretion. The biological activities of PRL are mediated by its binding to the PRL receptor (PRLR) in a one-to-two complex and regulated by tertiary structural properties. The sequence of events, high-affinity binding to the first subunit of the receptor, association of a lower-affinity subunit into a ternary complex, followed by an intracellular cross-phosphorylation cascade, is common to the members of this cytokine receptor family. Based on 
fluorescence resonance energy transfer studies binding of the first receptor subunit to hPRL has been hypothesized to induce a conformational change in the hormone that increases the affinity for binding of the second receptor subunit. ${ }^{2}$ Site 2 is thus considered not competent for receptor binding in the free hormone. ${ }^{2}$

PRL is a member of the long-chain cytokine family and is closely related to growth hormone $(\mathrm{GH})$ and placental lactogen (PL), with both of which it shares $23 \%$ sequence identity. Whereas GH is able to bind to the GH receptor (GHR) and for primates GH to PRLR, PRL (and non-ruminant PL) only binds PRLR. Ruminant PL may also bind heterodimers of homologous PRLR and GHR. ${ }^{3}$ The structural basis for the cross-reactivity observed between primate GH and PRLR but not between PRL and GHR is of fundamental importance for a full understanding of PRL biology. Binding of GH to GHR, of primate GH to PRLR and of PRL to PRLR has been studied thoroughly by site-directed mutagenesis, and residues contributing to the binding energy have been identified. ${ }^{4-9}$ Different subsets of residues define the binding surfaces in each hormone-receptor complex.

Several other facets of prolactin biology can benefit from knowledge of an accurate, highresolution solution structure. A precise determination of the 3D structure is an important platform for the design of molecules with agonistic and antagonistics properties, ${ }^{10-12}$ as this certainly will enhance the molecular understanding and guide the design. Moreover, an N-terminal fragment of both rat PRL ${ }^{13}$ and of human PRL (hPRL), ${ }^{14,15}$ the 16K-PRL, has been shown to be a potent antiangiogenic factor either in vitro or in vivo that significantly reduces tumor growth. Comparative structural studies may reveal important insight into the functional determinants of this process. Recently, hPRL was shown to interact with cyclophilin B, which facilitates transport of hPRL to the nucleus where the hPRL-cyclophilinB complex induces cell growth and proliferation. ${ }^{16,17}$

In order to elucidate the detailed molecular interactions between PRL and its diverse interacting partners, an accurate, high-resolution structure is essential. Here, we report a highresolution NMR solution structure of unbound hPRL and studies of its interaction with the extracellular domain of human prolactin receptor. A key finding is that our results do not support recent findings of conformational changes in the hormone upon receptor binding. Our data challenge conventional wisdom and establish a sound structural platform for further studies on PRL interactions.

\section{Results}

\section{Assignment of prolactin at $\mathrm{pH} \mathbf{8 . 0}$}

From the set of recorded triple-resonance spectra, backbone resonance assignments for 140 residues could be obtained. From ${ }^{13} \mathrm{C}$-NOESY-HSQC and HCCH-TOCSY spectra side-chain resonances for 182 residues could be assigned. For the 42 residues for which no backbone assignments were obtained, the side-chain assignments were based on NOEs in combination with preliminary structures. For 17 residues (Leu15, Gly47, Gly49, Thr52, Cys58, His59, Glu67, Gln77, Gln106, Glu110, Glu140, Gly152, Pro154, Ser155, Gln157, Glu161, and His195) no assignments were obtained. These residues are mainly located in loop regions. In total, $83 \%$ of all backbone, aliphatic and aromatic protons were assigned.

\section{Structure determination}

The solution structure of human PRL at $\mathrm{pH} 8$ and $37^{\circ} \mathrm{C}$ was solved on the basis of a total of 2550 restraints (Table 1). A final set of 200 structures was calculated using X-plor-NIH and 20 structures with the lowest energy and no restraint violations larger than $0.4 \AA, 5^{\circ}$, and $1 \mathrm{~Hz}$ for NOEs, dihedral angles and residual dipolar couplings (RDCs), respectively, were selected to represent the structure. The backbone atoms for residues in the four major $\alpha$-helices of the 20 structures were aligned with an RMSD to the mean structure of $0.32( \pm 0.05) \AA$ (Figure 1$)$. The RMSD to the mean for the backbone atoms of all residues in the structural alignment is $1.7( \pm 0.4) \AA$.

Table 1. Summary of structural statistics for all 20 structures (1RW5)

\begin{tabular}{lc}
\hline A. Experimental restraints & \\
Distance restraints & 2149 \\
Total & 389 \\
Intra residue & 470 \\
Sequential & 633 \\
Medium range & 657 \\
Long range & \\
Dihedral angle restraints (TALOS) & 176 \\
$\Phi$ & 144 \\
$\Psi$ & 81 \\
Residual dipolar couplings & \\
B. Restraints violations & 6 \\
NOE violations >0.3 A & 0.34 \\
Largest NOE violation (A) & $0.03 \pm 0.00$ \\
NOE RMSD & 0 \\
Dihedral angle violations > 5 & 3.88 \\
Largest dihedral angle violation (deg.) & $0.18 \pm 0.05$ \\
Dihedral angle RMSD & 0 \\
RDC violations > Hz & 0.99 \\
Largest RDC violation (Hz) & $5.1 \pm 0.2$ \\
R-factor for RDC (\%) & \\
C. Ramachandran plot & 87.4 \\
Most favored regions (\%) & 11.9 \\
Additionaly allowed regions (\%) & 0.6 \\
Generously allowed regions (\%) & 0.1 \\
Disallowed regions (\%) & \\
D. RMSD of atomic positions ( $\AA)^{\mathrm{a}}$ & $0.32 \pm 0.05$ \\
Backbone & $0.85 \pm 0.04$ \\
Heavy atoms & \\
\hline a Calculated as RMSD to the mean structure for residues in the \\
four long helices (residues 15-43, 78-103, 111-137 and 161-193). \\
\hline
\end{tabular}


(a)
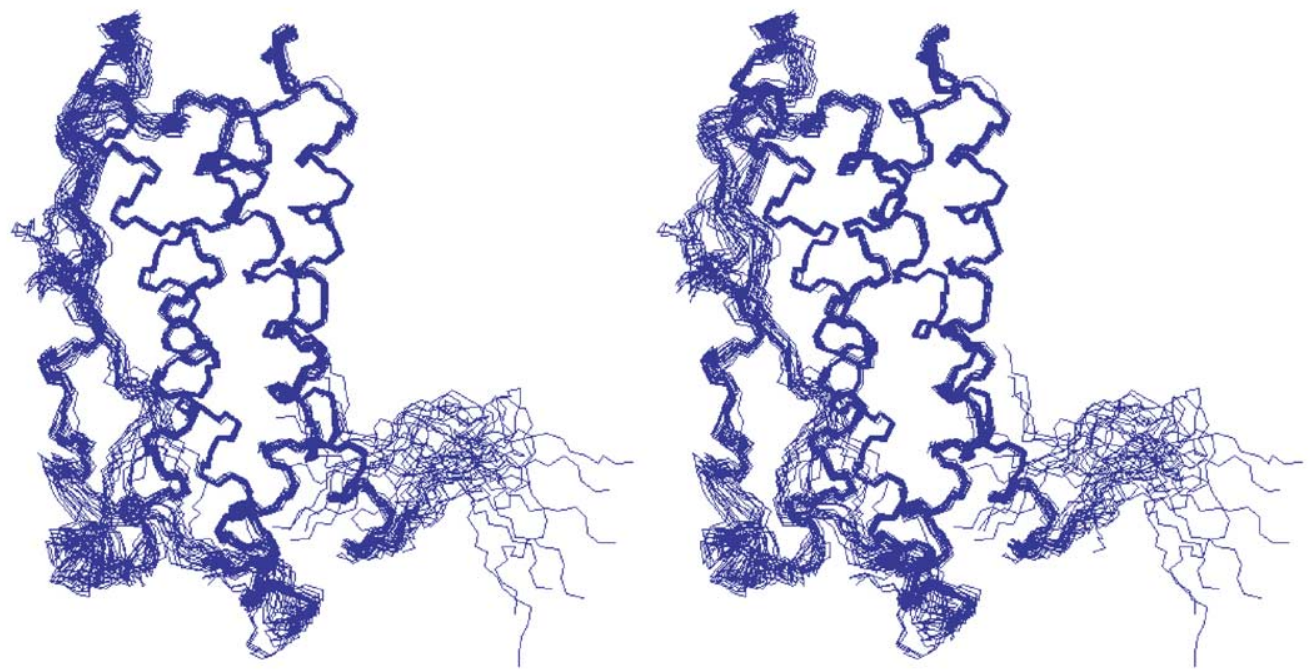

(b)
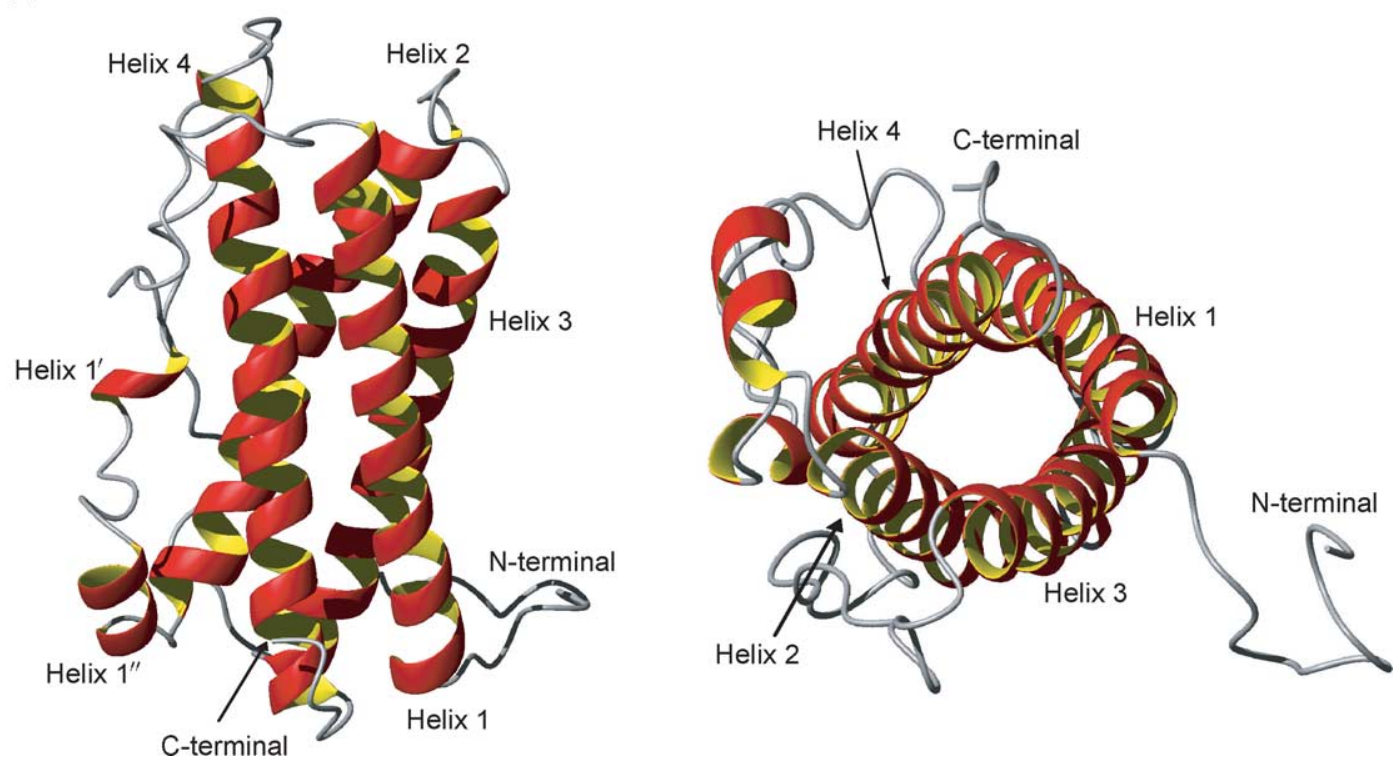

Figure 1. Solution structure of human prolactin. (a) Stereo view of the ensemble of the 20 lowest energy structures of 1RW5 solved by NMR spectroscopy. The backbone atoms $C, C^{\alpha}, N$ of the four major $\alpha$-helices (Leu15-Arg43, Lys78Arg103, Ala111-Val137, and Glu161-Ile193) were used for aligning the structures. (b) Ribbon representation of the lowest energy structure with the helices labeled accordingly. To the left is seen the hormone from the side and to the right the hormone is tilted $90^{\circ}$ backwards and viewed from the bottom.

\section{Secondary structure}

The secondary structure content of the ensemble was calculated with DSSPcont. ${ }^{18}$ Four major $\alpha$-helices are present in the structure from Leu15 to Arg43 (helix 1), Lys78 to Arg103 (helix 2), Ala111 to Val137 (helix 3) and Glu161 to Ile193 (helix 4). A short 310 -helix is present from Thr60 to Ser62 (helix $1^{\prime}$ ) and a short $\alpha$-helix is present from Lys69 to Gln74 (helix 1").

\section{Tertiary structure}

The core of the human PRL structure is made up by the four major $\alpha$-helices that wind slightly around each other (Figure 1). Inter-helical angles are between $18.5^{\circ}$ and $38.8^{\circ}$. The helices group in two antiparallel pairs, helix 1 /helix 4 and helix $2 /$ helix 3, each pair being packed more closely together and with their helical axis more nearly parallel as compared with the helices of the other pair. The minor helices are found in the overhand loop connection between helix 1 and helix 2 . Helix $1^{\prime}$ is tethered to helix 4 by a disulfide bond from Cys58 (just before the beginning of helix $1^{\prime}$ ) to Cys174. A total of 32 NOEs between Ile55 to Leu63 to the rest of the molecule determine the orientation of helix $1^{\prime}$ to be nearly parallel with helix 2 . The 
(a)

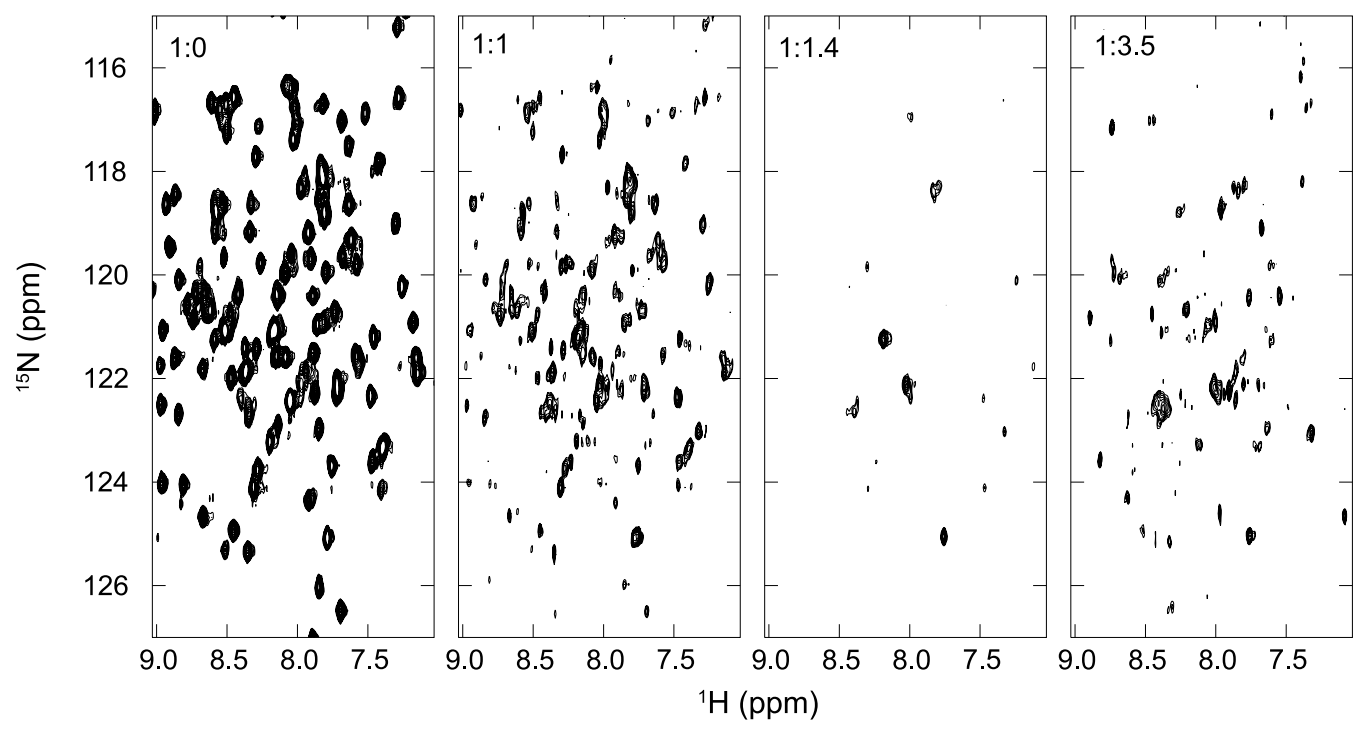

(b)

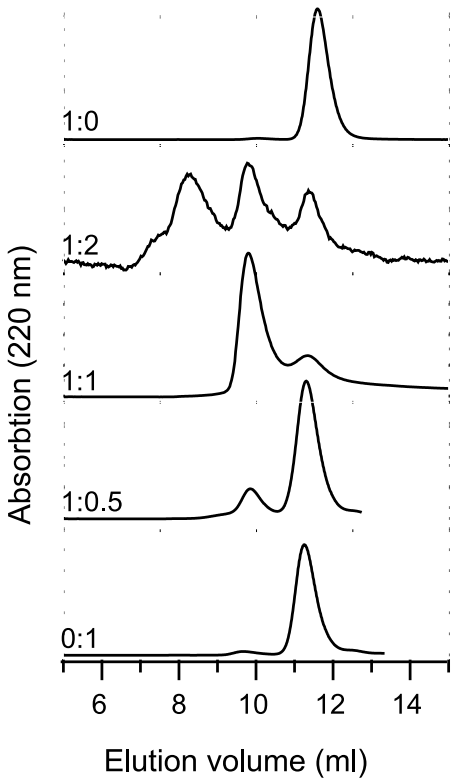

(c)

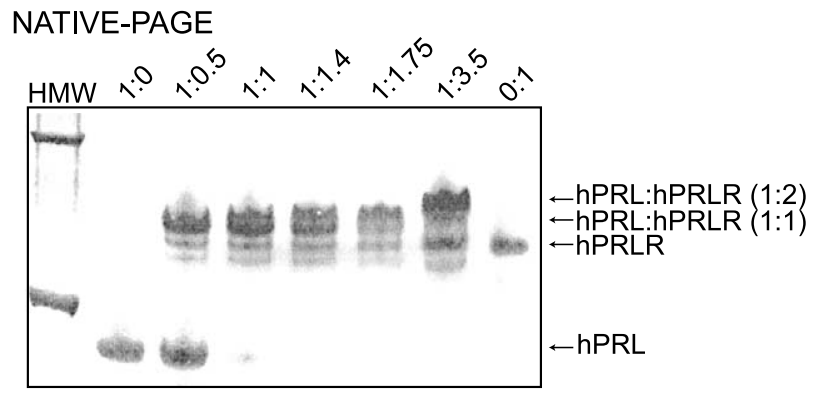

SDS-PAGE

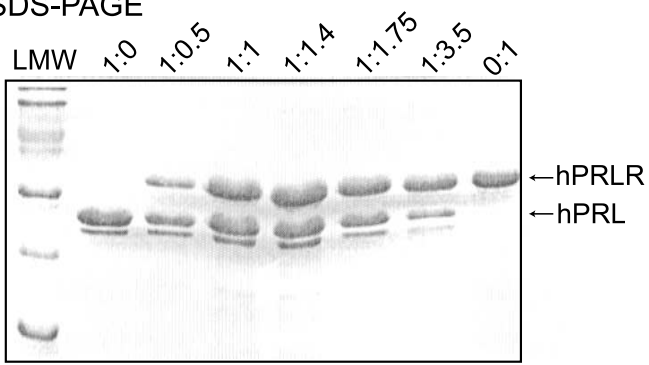

Figure 2. Hormone-receptor interactions studies. (a) ${ }^{1} \mathrm{H}_{1}^{15} \mathrm{~N}-\mathrm{TROSY}-\mathrm{HSQC}$ NMR spectra of ${ }^{15} \mathrm{~N}-\mathrm{hPRL}$ with an increasing amount of unlabeled hPRLR-ECD. On top of each spectrum is shown the ${ }^{15} \mathrm{~N}-\mathrm{hPRL}$ :hPRLR-ECD stoichiometry. (b) Gel filtration of hPRL:hPRLR-ECD samples in $25 \mathrm{mM}$ Tris- $\mathrm{HCl}$ (pH 8.0), $150 \mathrm{mM} \mathrm{NaCl}$ run at ratios 0:1, 1:0.5, 1:1,1:2, and 1:0. Absorption was measured at $220 \mathrm{~nm}$. (c) Extracts from the NMR samples of ${ }^{15} \mathrm{~N}-\mathrm{hPRL}-\mathrm{hPRLR}-$ ECD complexes from (a) analyzed by native PAGE (top) and by SDS-PAGE (bottom). HMW, high molecular mass markers (67 kDa and $140 \mathrm{kDa}$ ); LMW, low molecular mass markers (14.2 kDa, 20.1 kDa, $30.0 \mathrm{kDa}, 43.3 \mathrm{kDa}, 66.3 \mathrm{kDa}$ and $96.4 \mathrm{kDa})$. In the top panel of both gels is listed the ${ }^{15} \mathrm{~N}-\mathrm{hPRL}$ :hPRLR-ECD ratios of the samples. hPRLR-ECD runs at higher molecular mass than expected due to the $\mathrm{C}$-terminal $\mathrm{His}_{6}$-tag. The small band observed below the hPRL band in the gel is due to incomplete reduction by DTT.

conformation of helix $1^{\prime \prime}$ is well determined with a RMSD value of $0.1 \AA$ for the backbone atoms of the six residues. The orientation of helix $1^{\prime \prime}$ is constrained by five NOEs to helix 2 and helix 4 . The Nterminal part of the protein is highly flexible relative to the rest of the protein. The backbone confor- mations of Ile3-Gln12 are nevertheless fairly well defined (RMSD value of $1 \AA$ ), presumably owing to the restricted conformational freedom conferred by a disulfide bond between residues 4 and 11. The $\mathrm{C}$ terminus is restricted by a disulfide bond between residues 191 and 199, resulting in the 
packing of the last five non-helical residues against helix 4.

\section{Receptor binding studies}

Titration of ${ }^{15} \mathrm{~N}-\mathrm{hPRL}$ with increasing amounts of the extracellular domain of the human prolactin receptor (hPRLR-ECD) was followed by ${ }^{15} \mathrm{~N},{ }^{1} \mathrm{H}$ TROSY-HSQC spectra (Figure 2(a)). Addition of increasing amounts of hPRLR-ECD to a solution of ${ }^{15} \mathrm{~N}$-hPRL resulted in a gradual decrease in the intensity of all peaks originating from the unbound hormone. At 1.4 equivalents of receptor, the intensity of most peaks had decreased beyond detection. The decrease in intensity of the peaks from the unbound hormone at molar ratios of 1:0, 1:0.5, and 1:1 samples did not reveal any clear residue-specific variation (data not shown). The positions of the peaks from the unbound hPRL are insensitive to the relative amount of hPRLR-ECD, and unbound hPRL must thus be in slow exchange with the binary hormone-receptor complex on the NMR time-scale. The failure to observe peaks from the binary complex is likely the result of exchange between an encounter complex and the fully formed hormone-receptor complex at an intermediate rate on the NMR time-scale. Further addition of hPRLR-ECD resulted in the appearance of a new set of peaks. The intensities of this new set of peaks continue to increase up to a molar ratio of 1:3.5, which is the largest excess of receptor tested. The positions of the peaks do not change substantially with increasing amounts of hPRLRECD. We presume that these peaks result from the formation of a ternary complex of one hPRL bound to two hPRLR-ECD. The results of the NMR titration presented here are qualitative and do not allow the determination of any thermodynamic or kinetic parameters of the receptor binding process.

The NMR titration results suggest that hPRL binds to human PRLR-ECD in a one-to-two stoichiometry. This is confirmed both by gel filtration experiments with peaks corresponding to $49 \mathrm{kDa}\left(1: 1, K_{\mathrm{av}}=0.13\right)$ and $>75 \mathrm{kDa}\left(1: 2, K_{\mathrm{av}}=0.03\right.$, outside column capacity) (Figure 2(b)), and by native PAGE, where bands at masses corresponding to both the 1:1 and to the 1:2 complexes can be identified (Figure 2(c)). This, together with the receptor titration followed by NMR (Figure 2(a)) indicates that binding of the second receptor molecule is stronger than previously anticipated. ${ }^{19}$ More likely, as recently suggested, the affinity for the second receptor molecule increases significantly when site 1 is occupied. ${ }^{2}$ Still, site 1 has a higher affinity for hPRLR-ECD compared to the induced affinity of site 2, as native PAGE or gel filtration at sub-stoichiometric amounts of hPRLR-ECD and hPRL observes no ternary complex. At more than one equivalent of hPRLR-ECD, both binary and ternary complexes are observed by native-PAGE and gel filtration.

\section{Discussion}

\section{Comparison to 1N9D}

Alignment of the present structure at $\mathrm{pH} 8$ (PDB entry 1RW5) with the recently published solution structure of human prolactin at $\mathrm{pH}$ 6.8, (PDB entry 1N9D), ${ }^{20}$ shows significant and unexpected differences in the geometry, arrangement and orientation of the well-ordered parts of the molecule (Figure 3). Especially distinct are the differences in the regularity of the long helices and the orientation of the short helix $1^{\prime \prime}$. Comparison of the two sets of NOEs reveals fundamental differences. After reducing the NOE restraints by counting pairs of methylene protons and pairs of methyl groups as only one pseudo-atom, the number of NOE restraints for 1N9D was reduced to 2462 and for 1RW5 it was reduced to 2117. Comparing these reduced sets of NOEs showed only 328 NOEs common to both. When comparing only NOEs derived from a ${ }^{13} \mathrm{C}$-NOESY-HSQC of the aliphatic region, only 142 of the 1365 NOEs reported between aliphatic protons for the 1N9D structure are found in the NOE set for the present structure. The conflict is also readily apparent from an overlaid plot of the

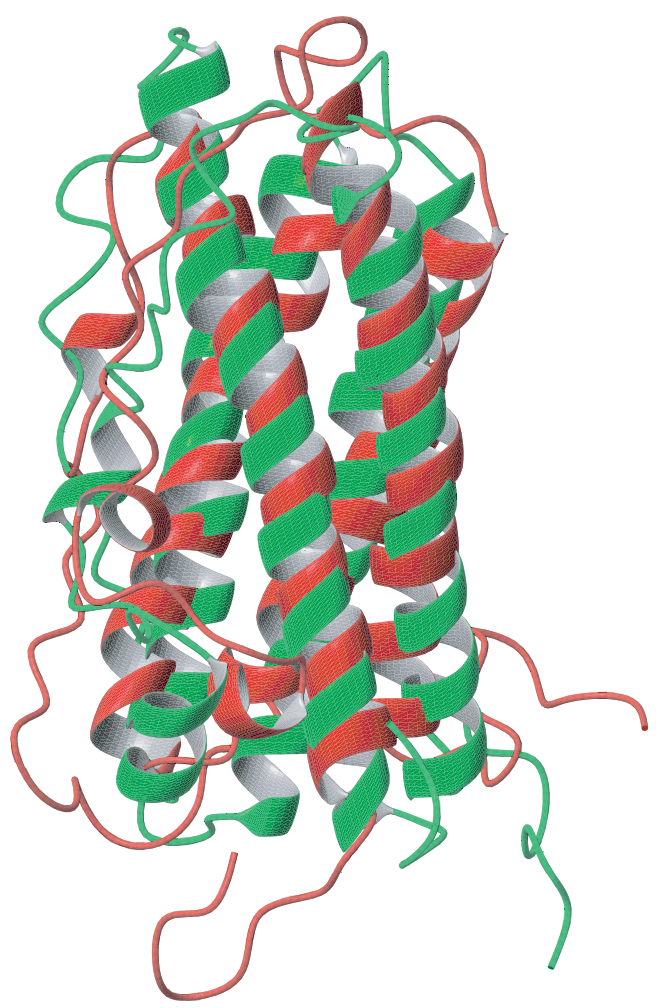

Figure 3. Comparisons of prolactin structures. Structural alignment of two solution structures of human prolactin. In green is the structure from this work (model 1 of the ensemble), in red the structure from PDB entry 1N9D (model 1 of the ensemble). Backbone atoms in the four major helices (residues 15-43, 78-103, 111-137, and 161-193) were used for the alignment. The two structures fit with an RMSD value of $3.8 \AA$. 
(a)

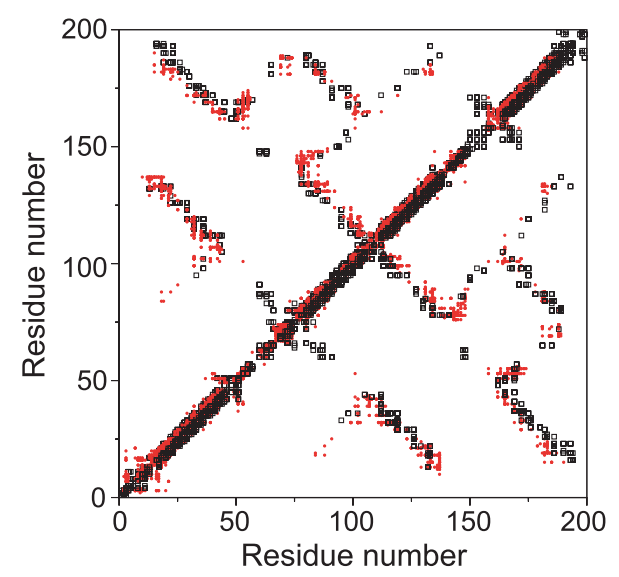

(b)

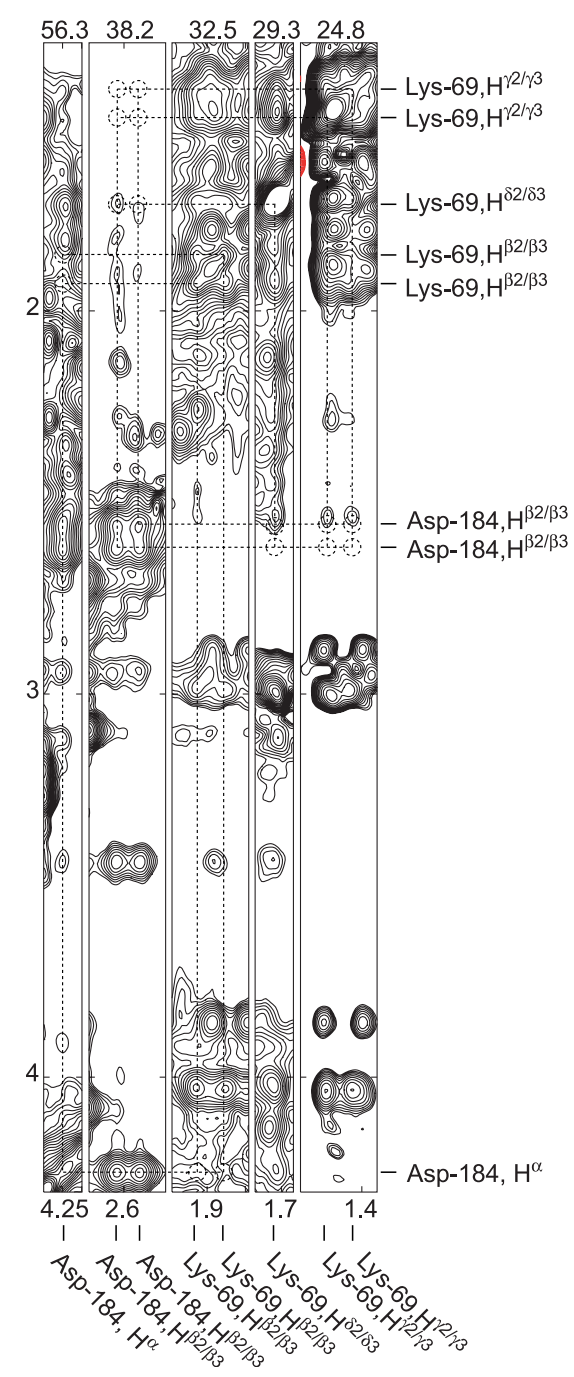

Figure 4. Comparison of experimental data. (a) Overlay of NOEs used for the structure calculation of 1RW5 (open squares) and 1N9D (red dots). The Figure is symmetric around the diagonal, except that the red dots are on top above the diagonal and the open squares are on top below the diagonal. (b) Strip-plot of spin-systems Lys69 and Asp184 from ${ }^{13} \mathrm{C}$-NOESY-HSQC recorded at $\mathrm{pH} 6.8$ in $100 \mathrm{mMNaCl}$. The dotted circles indicate the positions of NOE cross-peaks expected from the NOE restraint list of 1N9D.
NOEs from the two structures (Figure 4(a)). In order to ensure that structural changes with $\mathrm{pH}$ are not the cause of this difference, a 3D- ${ }^{13} \mathrm{C}-\mathrm{NOESY}-\mathrm{HSQC}$ was recorded on a sample of ${ }^{13} \mathrm{C},{ }^{15} \mathrm{~N}-\mathrm{hPRL}$ in $100 \mathrm{mM} \mathrm{NaCl}$ at $\mathrm{pH}$ 6.8. This spectrum appears similar to the $3 \mathrm{D}^{13} \mathrm{C}-\mathrm{NOESY}-\mathrm{HSQC}$ recorded at $\mathrm{pH}$ 8 that was used for NOE assignment in the present work. Although we have not performed an exhaustive analysis of the $\mathrm{pH} 6.8$ NOESY-HSQC spectrum, none of the NOEs reported by Keeler et al. ${ }^{20}$ which we had not already found in our analysis of the $\mathrm{pH} 8$ spectrum, were found in the spectrum recorded at pH 6.8 (Figure 4(b)).

The structure of 1N9D was analyzed by ProsaII, ${ }^{21}$ which is designed to identify erroneous structures. Several parts of the 1N9D structure show positive energies in the ProsaII analysis (data not shown). Along with the energy calculations, ProsaII performs a hide-and-seek test of a protein structure, where a given structure is hidden in a 50,000 residue poly-protein. The amino acid sequence corresponding to the hidden structure is dragged along this poly-protein in order to find the conformation with the lowest energy for the sequence. In the case of the $C^{\beta}-C^{\beta}$ energy, between 84 and 796 conformations accommodate the sequence of hPRL better than the 20 structures of 1N9D. For comparison, no conformation accommodates the hPRL sequence better than the 20 conformations of the present structure. Analysis of the structure by WHAT-CHECK ${ }^{22}$ similarly questions the accuracy of the 1N9D structure. A summary of the WHAT-CHECK structural Z-scores of both 1N9D and the present structure is listed in Table 2. By comparison of the NOE restraints deposited with 1N9D with the set of NOEs of 1RW5, we conclude that the poor quality of $1 \mathrm{~N} 9 \mathrm{D}$ is caused by a very large number of misassigned NOEs and the complete absence of aromatic resonance assignments.

Evaluation of empirical potential energies using the AMBER force field ${ }^{23,24}$ also reveals significant differences between 1RW5 and 1N9D. The average van der Waals energy for the 201 N9D structures is $4585 \mathrm{kcal} / \mathrm{mol}$, while the average value for the structures comprising $1 \mathrm{RW} 5$ is $844 \mathrm{kcal} / \mathrm{mol}$. The average total potential energies are +1945 and $-2735 \mathrm{kcal} / \mathrm{mol}$, respectively. Thus, the structures

Table 2. WHAT-CHECK structural Z-scores of hPRL structures

\begin{tabular}{lrr}
\hline PDB entry & 1N9D & 1RW5 \\
\hline 2nd generation packing quality & -3.055 & -1.495 \\
Ramachandran plot appearance & -7.195 & -1.376 \\
Chi-1/chi-2 rotamer normality & -6.890 & 0.117 \\
Backbone conformation & -11.282 & -5.956 \\
\hline
\end{tabular}

The Z-score expresses the number of standard deviations that a score diverges from the expected value (the average from a set of high quality structures). A positive $Z$-score indicates that the score is better than average and a negative $Z$-score indicates that the score is worse than average. 
comprising PDB entry 1N9D exhibit substantial energetic strain compared to 1RW5.

\section{Comparison to $\mathrm{GH}$ and $\mathrm{PL}$}

The structure of hPRL presented here is the first accurate structural representation of an unmodified lactogenic hormone in its unbound state. This permits for the first time a detailed structural comparison of the receptor bound ovine placental lactogen (oPL) and unbound hPRL with bound and unbound human $\mathrm{GH}(\mathrm{hGH})$. An overview of a three-dimensional structural alignment between a representative set of structures is listed in Table 3 and shown in Figure 5(a) and (b).

The three-dimensional structural alignment of hPRL in its unbound state and oPL bound to the extracellular domain of the prolactin receptor from rat $^{25}$ shows two highly similar structures with $89 \%$ of the $C^{\alpha}$ atom aligning within $2 \AA$ (Table 3 ). In order to account for the increased affinity at site 2 when site 1 is occupied, it has been widely speculated that prolactin may undergo substantial structural changes upon binding to the prolactin receptor. $^{2}$ From the structural comparison of unbound hPRL and bound oPL it appears, however, highly unlikely that such a conformational change occurs. Some electron density from residues of the loop between helix 1 and helix 2 is missing in the oPL-rPRLR crystal structure but structural alignment with the present structure does not suggest substantial ( $>2 \AA$ ) structural changes. Comparison of helix crossing angles in the free form of hPRL and in the bound form of oPL shows almost no differences. The largest difference is a $4^{\circ}$ change in the orientation of helix 2 relative to helix 3 . Also in receptor-bound oPL, a short helix (residues Trp151Thr158) in the loop between helix 3 and 4 is observed. At the similar position in hPRL, no helix is observed. This is, however, in a part of hPRL where many assignments are missing.

The structures of human GH in its unbound state, bound to either one or two GHR or bound to one
PRLR have been described. ${ }^{7,26-28}$ In brief, no major structural changes take place in hGH upon receptor binding and all the structures of hGH are highly similar, with one exception. In the loop between helices 1 and 2, hGH forms a mini-helix (residues Lys38-Asn47) when either unbound or bound to one or two GHR molecules. This mini-helix has been observed to adopt different orientations depending on crystal packing, and shows high plasticity in response to changing environment. It rotates its orientation by $23^{\circ}$ relative to the bundle core when comparing the unbound to the bound forms of $\mathrm{hGH}{ }^{26}$ In an affinity-matured form of hGH, many mutated positions do not directly interact with the receptor, but are positioned in this mini-helix and may stabilize the otherwise inherent flexibility of this region. ${ }^{26}$ Interestingly, in the structure of hGH bound to hPRLR, this minihelix is unravelled at its $\mathrm{N}$ terminus and is only three residues long (Figure 5(a) and (b)).

Compared to hGH, about $80 \%$ of the $\mathrm{C}^{\alpha}$ atoms of both hPRL and oPL align within $2 \AA$ (Table 3 ). A structural alignment of hPRL, oPL in complex with rPRLR and hGH both unbound, bound to one and two hGHR and bound to one hPRLR is shown in Figure 5(a). The structures are aligned to hPRL by their $C, C^{\alpha}$ and $N$ atoms using a total of 120 residues. A sequential overview of the structural alignment is shown in Figure 5(b).

Four clear differences between the structures are evident from the alignments. Firstly, neither hPRL nor oPL form the first mini-helix of hGH in the beginning of the overhand loop between helices 1 and 2, although electron density is missing for some of the loop-residues in oPL (Figure 5(a), I). Instead, this loop region of lactogens aligns effectively with the loop structure formed by hGH bound to hPRLR. This clearly demonstrates the plasticity of this part of hGH, as described earlier. Secondly, there are two inserts in the apical end of the lactogenic hormones clearly protruding, unrestricted, from the hormones compared to the loop of $\mathrm{GH}$ that bends forward (Figure 5(a), II). Thirdly, in the overhand loop

Table 3. Structural comparisons of hGH, oPL and hPRL

\begin{tabular}{|c|c|c|c|c|c|c|}
\hline & 1HUW & $\begin{array}{c}\text { GH-GHR } \\
1: 1 \\
1 \mathrm{~A} 22\end{array}$ & $\begin{array}{c}\text { GH-GHR } \\
1: 2 \\
3 \mathrm{HHR}\end{array}$ & $\begin{array}{c}\text { GH-PRLR } \\
1: 1 \\
1 \mathrm{BP} 3\end{array}$ & $\begin{array}{c}\text { PL-PRLR } \\
1: 2 \\
1 \mathrm{FGF}\end{array}$ & 1N9D \\
\hline PRL (\%) & 86.7 & 78.4 & 78.9 & 82.2 & 89.2 & 61 \\
\hline 1RW5 (丹) & 1.69 & 1.53 & 1.56 & 1.70 & 1.49 & \\
\hline $\mathrm{GH}(\%)$ & & 91.0 & 92.2 & 92.2 & 81.0 & 63.3 \\
\hline Unbound ( $\left({ }^{\prime}\right)$ & - & 1.19 & 0.69 & 1.17 & 1.24 & \\
\hline GH-GHR (\%) & & & 96.7 & 93.3 & 79.4 & 68.3 \\
\hline $1: 1(\AA)$ & - & - & 0.69 & 1.22 & 1.13 & \\
\hline GH-GHR (\%) & & & & 94.1 & 80.3 & 64.5 \\
\hline $1: 2(\AA)$ & - & - & - & 1.21 & 1.21 & \\
\hline GH-PRLR (\%) & & & & & 79.8 & 65.3 \\
\hline $1: 1(\AA)$ & - & - & - & - & 1.19 & \\
\hline PL-PRLR (\%) & & & & & & 60 \\
\hline $1: 2$ & - & - & - & - & - & \\
\hline
\end{tabular}

For each comparison, the Table gives the percentage of aligned $\mathrm{C}^{\alpha}$ atoms of maximum number possible, together with the RMSD value of this alignment. 
(a)
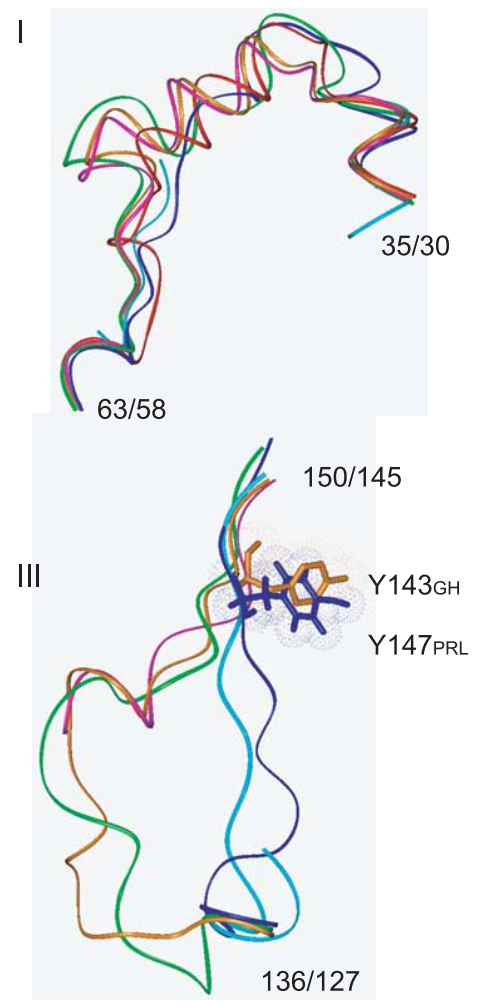

II
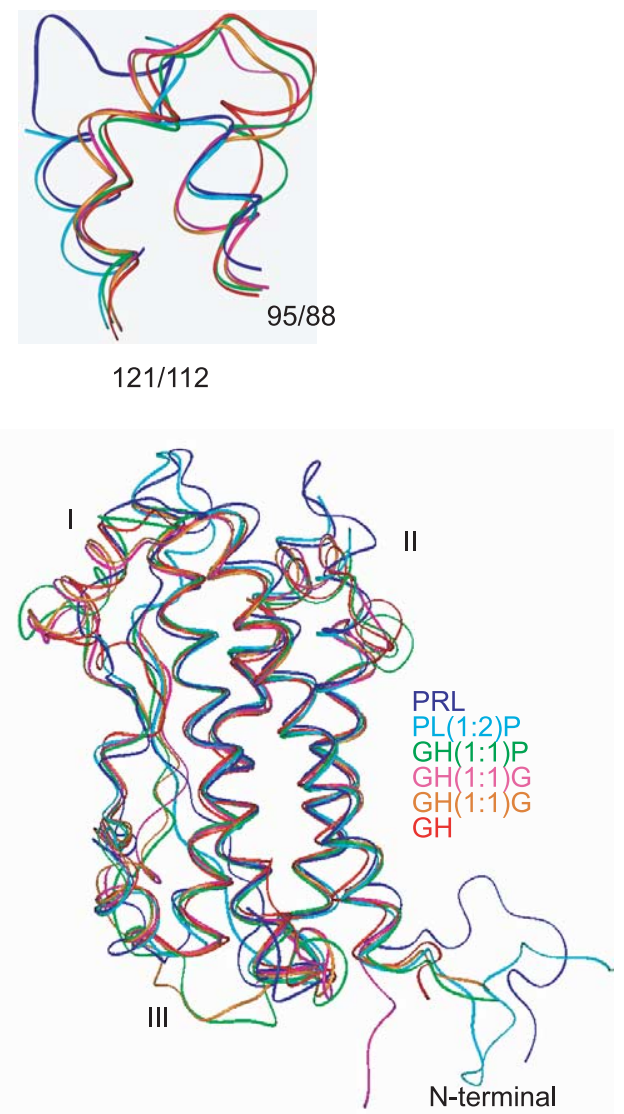

(b)

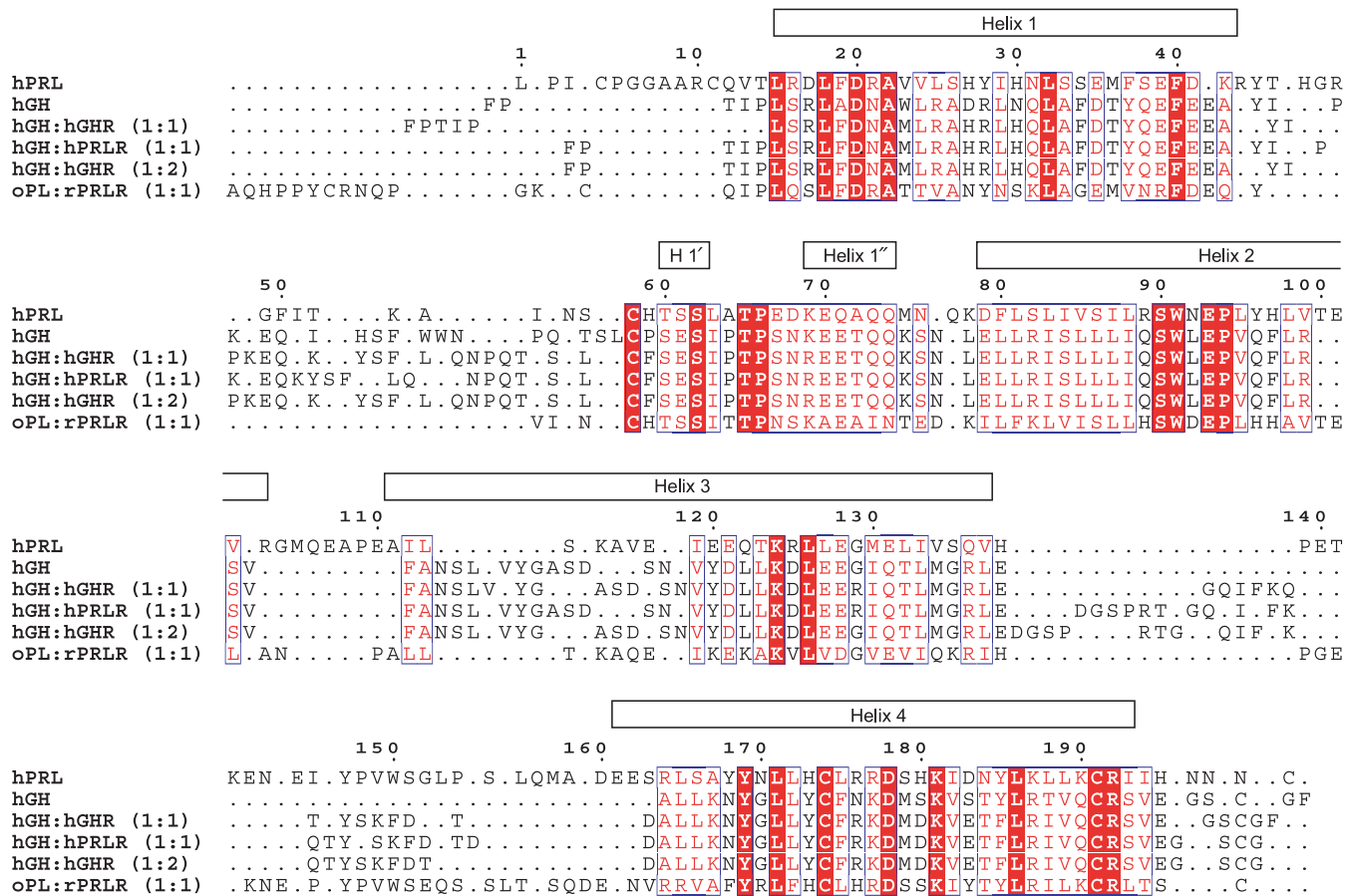

Figure 5. Structural alignment of oPL, hGH and hPRL. (a) Ribbon representation of unbound hPRL (blue; PDB code, 1RW5), oPL bound to rPRLR (cyan; PDB code, 1F6F), unbound hGH (red; PDB code, 1HUW), hGH bound to hGHR (1:1, magenta; PDB code, 1A22), hGH bound to hGHR (1:2, orange; PDB code, 3HHR) and hGH bound to hPRLR (1:1, green; PDB code, 1BP3) aligned by MODELLER. I, Zoom on the GH mini-helix in the first overhand connection; II, zoom on the first hPRL insert; III, zoom on the second overhand connection. GH, growth hormone; PL, placental lactogen; PRL, prolactin; G, growth hormone receptor ECD; P, prolactin receptor ECD.(b) Text representation of a structural alignment of hPRL (PDB code, 1RW5), hGH (PDB code, 1HUW), hGH:hGHR (1:1) (PDB code, 1A22), hGH:hPRLR (1:1) (PDB code, 1BP3), hGH:hGHR (1:2) (PDB code, 3HHR) and oPL:rPRLR (1:1) (PDB code, 1F6F). Identical residues are boxed red and similar residues are in red on a white background. The helices of hPRL are indicated by boxes. 
between helix 3 and helix 4, GH has a short structural insert in the beginning, whereas hPRL and oPL have a structural insert at the end of this loop (Figure 5(a), III). All three hormones align the middle four residues (from hPRL:Tyr147-Trp150) within $2.0 \AA$. The differences may be consequences primarily of the presence of a proline residue in both oPL and hPRL (hPRL-Pro139) that is absent in $\mathrm{hGH}$, and which directs the hPRL and oPL loops in the opposite direction to the hGH loop. Lastly, the short helix observed in the loop between helix 3 and helix 4 in receptor-bound oPL is not observed in any of the hGH structures. These differences are apparently not, except for the first loop structure where GH forms a mini helix, important for receptor binding, as no functional residues have been identified within these loop structures. Why these cytokines are so markedly different in their loop positions disjoint from their receptor binding sites remains to be investigated and fully understood. The loop inserts of hPRL may have to do with interactions to other proteins, as described above (e.g. cyclophilin), or may even be important for the generation of the smaller $16 \mathrm{~K}$ fragment.

\section{Receptor binding}

Despite the high level of structural homology of the three-dimensional structures of hGH, oPL and hPRL, different residues have been shown to be responsible for providing the binding energy and specificity of the interactions in the hGHhGHR complex, the hGH-hPRLR complex, the oPL-rPRLR complex and the hPRL-hPRLR complex. ${ }^{4,5,25,29,30}$ One significant difference between hPRL and hGH is the relative stability of the 1:2 complexes. For hGH the 1:2 complexes are stable, whereas hPRL has been suggested to form transient, unstable 1:2 complexes with homologous complexes formed even less tightly than heterologous complexes. ${ }^{19}$ This has led to the expectation that homologous complexes dissociate rapidly due to transient binding of the second receptor molecule. Here, it is suggested that hPRL and hPRLR-ECD forms tight 1:1 complexes, but also that 1:2 complexes can be formed with a stability that allows their detection by gel filtration. This is in contrast to earlier studies on rainbow trout, ${ }^{31}$ bovine, ${ }^{32}$ ovine $^{33}$ and rat PRL interacting with PRLR, ${ }^{19,34}$ all pointing towards unstable homodimerization reactions. To our knowledge, this is the first demonstration by gel filtration techniques of a stable 1:2 complex between a homologous hormone-receptor pair of human prolactin. The detections were done at micromolar concentrations of protein, suggesting sub-micromolar binding affinities. These findings are strongly supported by a recent determination of $K_{\mathrm{D} 1}$ and $K_{\mathrm{D} 2}$ values by surface plasmon resonance for each of the receptor binding sites in hPRL. Both dissociation constants are of the same order of magnitude and in the nanomolar range. ${ }^{2}$ Also, as expected, all three different techniques applied here confirm the sequential scenario of binding of two receptor molecules.

\section{Binding site 1}

Binding site 1 of hPRL has generally been assigned to the section bordered by helix 1, helix 4 , and the second half of loop 1 . Alanine scanning mutagenesis of loop 1 residues $^{5}$ and of residues in helix 1 and helix $4^{6,9}$ as determined using PRL from either human or rat, has identified 13 residues as important for site 1 binding. For helix 1, Val23, His 30 and Phe37 could be demonstrated to be important for receptor binding while for helix 4, Tyr169, His173, Arg176, Arg177, His180, Lys181, Tyr185 and Lys187 significantly altered both binding affinities and biological function. Loop 1 residues involved are His59, Pro66 and Lys69. The proposed site 1 receptor-binding site of PRL is shown in Figure 6(a). It is seen that aromatic residues, together with large hydrophobic and polar residues with many positive charges occupy the concave binding site, complementing the tryptophan and negatively charged residues of the receptor hot spots. ${ }^{35}$ Pro66 is not accessible to solvent, and Val23 and His59 are distal to the otherwise joint location of all of the remaining site 1 residues which, as suggested by earlier studies, confirm the relatively limited biological importance of these three residues. ${ }^{6}$ The remaining ten residues form a convincing receptor binding site. It could be further speculated that His27, Asn184, and Leu188 play a significant role in receptor binding as well. Although His 27 in both bovine and human PRL has been found not to be important for bioactivity, ${ }^{36,37}$ proteins mutated at Asn184 display up to $50 \%$ lower bioactivity. ${ }^{6}$ The three residues are close to the binding site and are solvent accessible.

\section{Binding site 2}

A hydrophobic channel is formed between helix 1 and helix 3 that outlines the second receptor binding site in hPRL. This site has been described as a flat binding surface that does not have distinct hot spots of residues responsible for most of the binding free energy. The affinity of binding site 2 for a receptor molecule is significantly lower than the affinity of site 1 . Upon binding of a receptor molecule at site 1, the affinity for binding of a second receptor molecule is substantially increased approaching the affinity of site $1 .^{2,19}$ From mutagenesis studies, Ala22, Arg21, Tyr28, Arg125 and Gly129 were shown to be important for receptor binding. $929,36,38$ Inspection of the putative binding site from an early structural model of PRL suggested a set of small residues to be important for maintaining the geometry of the site. ${ }^{39}$ The suggested site 2 receptor-binding site is shown in Figure 6(b), and from inspection of the architecture of this site, it is clear that a very hydrophobic channel is indeed observed, the base of which is formed mainly by the small Ala22 and Gly129, as 
(a)

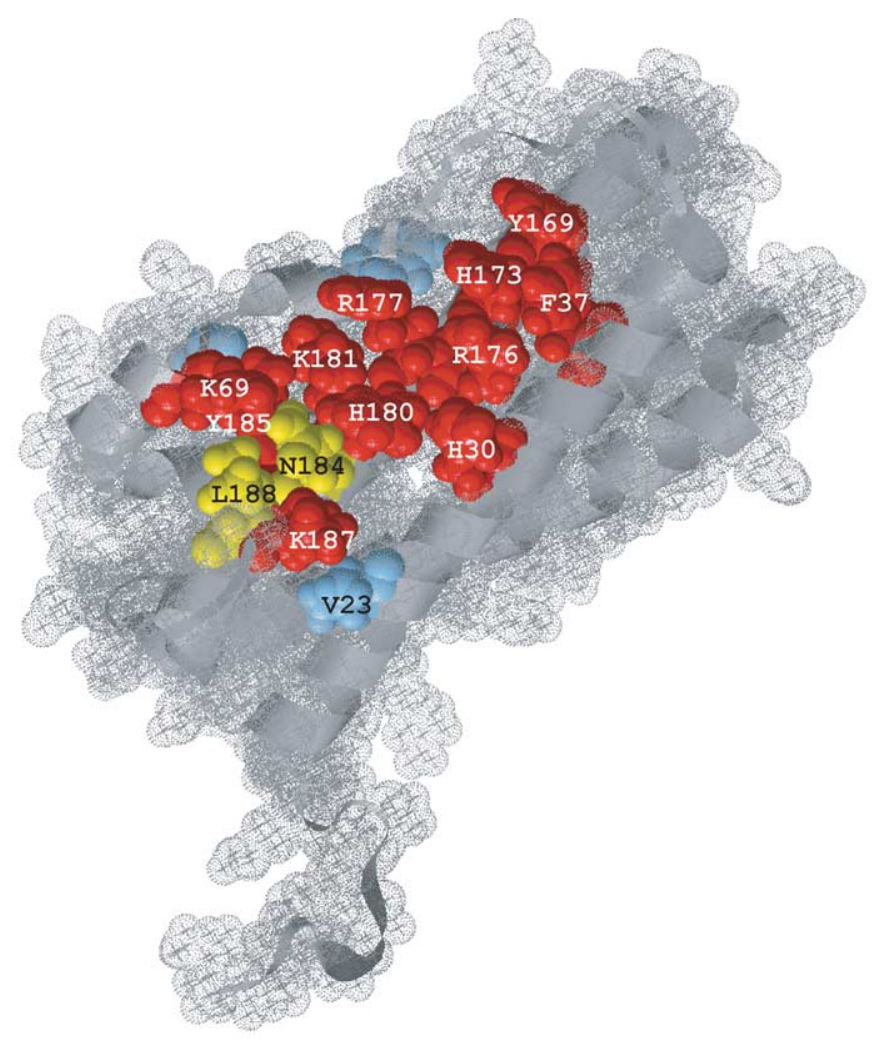

Figure 6. Suggested receptor binding sites 1 and 2 of hPRL. (a) Residues determined from earlier mutagenesis work are outlining the receptor-binding site 1 and are colored red. A subset of the residues are distant to the common binding site or not solvent accessible (not observable in the present display) and are colored blue (Val23, His59, Pro66). Residues that are speculated from this work to be involved in receptor recognition are Asn184 and Leu188 and are colored yellow. (b) Residues outlining the hydrophobic channel of receptor binding site 2 are shown in red space-filled atoms and the two small residues Ala22 and Gly129 structuring the floor of the channel are shown in white spacefilled atoms. Tyr28, known from earlier work to be important for receptor interaction is shown in orange space-filled atoms, and residues outside the channel investigated in earlier mutagenesis studies are shown in yellow spacefilled atoms. For both (a) and (b) a smooth ribbon drawn through the backbone atoms is shown in grey and residues not shown in color are shown as a surface representation.

pinpointed in earlier studies ${ }^{29,38}$ flanked by Leu126 and Ile133 at each side. The side-chains of Leu18, Arg21, Leu25, Arg125, Glu128 and Leu132 make up the interior wall of the hydrophobic channel, and the rim of the channel is extended by the inclusion of Tyr 28 on one side. The residues scanned in earlier studies $^{29}$ are positioned upstream compared to the hydrophobic channel, which may explain the modest effects observed in the alanine scan. This displacement of binding site 2 was already recognized in 1996 from a thorough description of the lactogenic sequence-function relationships. ${ }^{40}$ Our results indicate that the source of the increased affinity of site 2 upon binding a receptor molecule at site 1 is not due to conformational changes in hPRL. A major contribution to the binding of the ternary complex may stem from receptor-receptor inter- actions, as described in detail through mutation analysis for the ternary hGH-hGHR complex. ${ }^{41,42}$

The N-terminal residues of oPL have been suggested to play a critical role in receptor binding to site 2 , based on the identification of hydrogen bonds. ${ }^{25}$ Iterative truncation of the first 13 residues of hPRL either had no effect on the biological function, or if any, improved the biological activity. ${ }^{10,43}$ The removal of the N-terminal residues, however, does abolish the residual agonistic activity of the G129R antagonist. ${ }^{10,43}$ The N-terminal residues of $\mathrm{GH}$ do not contain crucial binding determinants for binding to the PRL receptor. $^{8}$ As removal of the first $14 \mathrm{~N}$-terminal residues of PRL reduced affinity and decreased bioactivity, this suggests a critical role of Thr14, either in receptor binding or in stabilizing helix 1 . In 
the present structure, Thr14 forms an N-terminal capping motif with the side-chain of Asp17, which clearly explains the destabilizing effect of removing this residue. The role of the extended $\mathrm{N}$ terminus of PRLs is more likely to promote zinc-dependent PRL aggregation or some other activity of hPRL as previously suggested. ${ }^{43,44}$

\section{The growth hormone-prolactin receptor interaction}

In $\mathrm{GH}$, residues in the first mini-helix, especially Phe44, together with the C-terminal residues of helix 2 and the N-terminal portion of helix 4 , have been shown to be important for hPRLR binding, but have no effect on binding to hGHR. ${ }^{45}$ Mutation of what was believed to be a corresponding residue in hPRL, Phe50, has almost no effect on hPRLR binding. ${ }^{46}$ However, based on the present structure of hPRL, Phe $44_{\mathrm{GH}}$ and Phe50 0 PRL do not align structurally (Figure 5(b)). Instead, Ile55 of hPRL is more likely the residue comparable to Phe44 of hGH. This may explain why no effect was observed for the Phe50 mutant. It was also suggested that for $\mathrm{hGH}$, residues of the first mini-helix couple binding at site 1 to structural changes in site 2 mediated by residues Phe44, Leu93, Tyr160, Tyr164 and Leu163. ${ }^{47,48}$ No similar effect has been identified for hPRL, although deletion of residues Asp41Thr52 decreased the lactogenic activity by a factor of 14,000 . This, however, also shifted the tryptophan fluorescence to higher wavelengths, an indication of decreased protein stability. ${ }^{46}$ The residues of hPRL corresponding to $\mathrm{GH}$ coupling residues are Ile55, Leu98, Tyr169, Leu172, and His173. Many of these residues are deeply buried, suggesting that large structural changes are likely to occur when substituted with the charged residue glutamate, as done for hGH.

Several studies have pointed to marked differences in receptor binding between hGH, oPL, and hPRL, both in terms of specificities and affinities. One explanation for the promiscuity of hGH in receptor preference compared to PRL may be sought in the absence of the mini-helix in the beginning of the loop separating helix 1 and helix 2 in hPRL and oPL. Thus, for the lactogenic activity of hGH, partial unravelling of the mini-helix is a prerequisite for correct presentation of the residues interacting with hPRLR, especially of Phe44. This built-in structural plasticity of hGH in this particular structural segment has been documented by several studies pointing to high flexibility in this area. $^{27,49}$ This flexibility may not be present in PL or PRL. We suggest that this mini-helix forms the basis for the promiscuity of $\mathrm{hGH}$ in its receptor interaction preferences.

\section{Conclusions}

Here, we have shown that the structure of hPRL in solution is highly similar to that of both oPL bound to rPRLR and hGH in various complexes. It is thus unlikely that any major structural rearrangement occur upon receptor binding. Significant differences in loop structures are found between the lactogenic and the somatotropic hormones. Although the binding of hPRL to hPRLR differs from the binding of hGH to hPRLR by the hot spot residues of the binding sites, it is proposed that intrinsic flexibility in the first overhand connection in $\mathrm{hGH}$ is a prerequisite for the broader receptor preference of the growth hormones. We have also shown that the present structure of hPRL convincingly confirms the positioning of both binding sites 1 and 2 obtained earlier from a large set of mutagenesis data. We have shown that hPRL and hPRLR-ECD forms a tight 1:1 complex but also that an apparent 1:2 complex can be formed with a stability that allows its detection by gel filtration. A significant finding emerging from this study is that the increased affinity for PRLR at the second receptor binding site of PRL when the first site is occupied does not result from an induced conformational change, but likely results from receptorreceptor interaction. This observation will both direct further experiments and provide a new perspective from which to view the substantial body of biochemical data on PRL-PRLR interaction.

\section{Methods}

\section{Purification of recombinant human prolactin}

hPRL, both unlabeled, ${ }^{15} \mathrm{~N}$-labeled, $\left({ }^{13} \mathrm{C},{ }^{15} \mathrm{~N}\right)$ labeled, and $\left[{ }^{13} \mathrm{C}\right]$ leucine-labeled was expressed in Escherichia coli BL21(DE3) from the pT7-hPRL vector as described. ${ }^{6,50}$ The protein was refolded from inclusion bodies by continuous dialysis at a protein concentration $<0.1 \mathrm{mg} /$ $\mathrm{ml}$ into $20 \mathrm{mM} \mathrm{NH} \mathrm{NCO}_{3}, 0.2 \mathrm{M} \mathrm{NaCl}(\mathrm{pH}$ 8) (40 l, 48 hours). Monomeric hPRL was purified using gel filtration on a Sephadex G-100 column, with $20 \mathrm{mM}$ $\mathrm{NH}_{4} \mathrm{HCO}_{3}, 0.05 \mathrm{M} \mathrm{NaCl}(\mathrm{pH} 8)$, and reduced hPRL was removed using a HiTrap Q-Sepharose column, with $20 \mathrm{mM}$ Tris- $\mathrm{HCl}(\mathrm{pH} 8.0)$ and a NaCl gradient from $0-0.5 \mathrm{M}$.

\section{NMR samples}

Samples of $\left[{ }^{15} \mathrm{~N}\right] \mathrm{hPRL},\left[{ }^{13} \mathrm{C},{ }^{15} \mathrm{~N}\right] \mathrm{hPRL}$ and $\left[{ }^{13} \mathrm{C}\right]$ leucinehPRL at a protein concentration of approximately $1 \mathrm{mM}$ were prepared in $2 \mathrm{mMNH}_{4} \mathrm{HCO}_{3}(\mathrm{pH} 8), 10 \%(\mathrm{v} / \mathrm{v})^{2} \mathrm{H}_{2} \mathrm{O}$. A sample of $1 \mathrm{mM}{ }^{13} \mathrm{C},{ }^{15} \mathrm{~N}-\mathrm{hPRL}$ in $100 \%{ }^{2} \mathrm{H}_{2} \mathrm{O}, 2 \mathrm{mM}$ $\mathrm{NH}_{4} \mathrm{HCO}_{3}(\mathrm{pH} 8)$, was also prepared. For measurements of residual dipolar couplings (RDCs) a partly aligned sample was prepared by addition of phage Pf1 to 0 . $7 \mathrm{mM}\left[{ }^{13} \mathrm{C},{ }^{15} \mathrm{~N}\right] \mathrm{hPRL}$ in $2 \mathrm{mM} \mathrm{NH} \mathrm{HCO}_{3}(\mathrm{pH} 8), 20 \%$ ${ }^{2} \mathrm{H}_{2} \mathrm{O}$. The phage resulted in a splitting of $6.5 \mathrm{~Hz}$ of the ${ }^{2} \mathrm{H}_{2} \mathrm{O}$ signal corresponding to a phage concentration of $6.5 \mathrm{mg} / \mathrm{ml}$. A matched isotropic sample of $0.7 \mathrm{mM}$ $\left[{ }^{13} \mathrm{C}^{15} \mathrm{~N}\right] \mathrm{hPRL}$ in $2 \mathrm{mM} \mathrm{NH} \mathrm{HCO}_{3}(\mathrm{pH}), 20 \%{ }^{2} \mathrm{H}_{2} \mathrm{O}$ was also prepared. For comparison to data by Keeler et al. ${ }^{20}$ a sample of $\left[{ }^{13} \mathrm{C},{ }^{15} \mathrm{~N}\right] \mathrm{hPRL}$ in $100 \mathrm{mM} \mathrm{NaCl}(\mathrm{pH}$ 6.8), $10 \%{ }^{2} \mathrm{H}_{2} \mathrm{O}$ was prepared. 


\section{Purification of the extracellular domain of recombinant prolactin receptor, hPRLR-ECD}

The sequence of the extracellular domain of the human prolactin receptor (hPRLR-ECD) was extracted from a cDNA library and fused to a C-terminal hexa-His-tag (hPRLR(Met0-Asp210)-GSRS-His ${ }_{6}$ ). This construct was expressed in E. coli BL21(DE3) cells from the pQE70 vector and refolded from inclusion bodies by simple dialysis into $50 \mathrm{mM}$ Tris- $\mathrm{HCl}(\mathrm{pH} 9.0), 150 \mathrm{mM} \mathrm{NaCl}$, $10 \mathrm{mM}$ cysteamin, $1 \mathrm{mM}$ cystamin $(3 \times 41)$, protein concentration $<0.1 \mathrm{mg} / \mathrm{ml}$. The refolded fraction was precipitated by addition of ammonium sulfate to $75 \%$ $(\mathrm{w} / \mathrm{v})$, and left for two hours with gentle stirring at room temperature. The precipitate was dissolved in MilliQ water and gel-filtered on Sephadex G-100 in $30 \mathrm{mM}$ $\mathrm{NH}_{4} \mathrm{HCO}_{3}, 0.1 \mathrm{M} \mathrm{NaCl}(\mathrm{pH}$ 8). Peak fractions were dialyzed against $20 \mathrm{mM}$ Tris- $\mathrm{HCl}(\mathrm{pH}$ 9.0). Reduced hPRLR-ECD was removed by passing the sample over a Q-Sepharose FF-column in $20 \mathrm{mM}$ Tris- $\mathrm{HCl}$ ( $\mathrm{pH} 9.0)$, with a linear gradient from $0-1 \mathrm{M} \mathrm{NaCl}$. The protein was concentrated and buffer exchanged on spin-columns into $2 \mathrm{mM} \mathrm{NH}_{4} \mathrm{HCO}_{3}, 10 \%{ }^{2} \mathrm{H}_{2} \mathrm{O}$ (pH 8.0).

\section{NMR spectroscopy}

For assignment, all NMR spectra were recorded at $310 \mathrm{~K}$ on a Varian INOVA 800 with a $5 \mathrm{~mm}$ tripleresonance probe equipped with a Z-field gradient. For sequential assignment the following spectra were recorded on the $\left({ }^{13} \mathrm{C}_{,}^{15} \mathrm{~N}\right)$ labeled sample in $10 \%{ }^{2} \mathrm{H}_{2} \mathrm{O}$ : HSQC, HNCO, HN(CA)CO, HNCA, HNCOCA, CBCA $\mathrm{CONH}$ and HNCACB. For side-chain assignment $\mathrm{C}(\mathrm{CO})$ $\mathrm{NH}, \mathrm{H}(\mathrm{CCO}) \mathrm{NH}$ and $\mathrm{HCCH}-\mathrm{TOCSY}$ spectra (with offsets at both the aliphatic and aromatic resonances, respectively) were recorded on the $\left({ }^{13} \mathrm{C}_{1}^{15} \mathrm{~N}\right)$ labeled sample in $100 \%{ }^{2} \mathrm{H}_{2} \mathrm{O}$. NOE assignments were based on a ${ }^{15} \mathrm{~N}-$ NOESY-HSQC (recorded on the ${ }^{15}$ Nlabeled sample), a ${ }^{13} \mathrm{C}-\mathrm{NOESY-HSQC}$ of the aliphatic region and $a{ }^{13} \mathrm{C}$ NOESY-HSQC of the aromatic region (both recorded on the $\left({ }^{13} \mathrm{C}^{15} \mathrm{~N}\right)$ labeled sample in $\left.100 \%{ }^{2} \mathrm{H}_{2} \mathrm{O}\right)$. All of the pulse-sequences were from the Varian Protein-Pack version 1.6C. For measurement of $\mathrm{NH}$ RDCs the $\mathrm{S}^{3} \mathrm{CT}$ experiment was applied. ${ }^{51}$ The spectra were processed using nmrPipe. ${ }^{52}$ For comparison to the data by Keeler et al. ${ }^{20}$ a ${ }^{13} \mathrm{C}-$ NOESY-HSQC of the aliphatic region was recorded at $\mathrm{pH} 6.8,100 \mathrm{mM} \mathrm{NaCl}$ and $298 \mathrm{~K}$.

\section{Assignment and structure calculation}

Sequential and side-chain assignments were performed manually using Pronto3D. ${ }^{53}$ Initially NOEs were assigned automatically using the CANDID routine in Cyana. ${ }^{54}$ The assignments obtained from CANDID were analyzed in Pronto3D and peak-lists corrected prior to a new round of automated NOE assignment. After several rounds of automated NOE assignment, the NOE assignments were finalised by several rounds of manual assignment. Final structure calculations were performed in Xplor-NIH, ${ }^{55}$ including a conformational database potential ${ }^{56}$ and the measured NH RDCs in the refinements. Two hundred structures were calculated and from these 20 structures with the lowest overall energy and fewest restraint violations were chosen to represent the structure of hPRL. Structures were visualized using MOLMOL $^{57}$ and INSIGHTII (MSI) and structural alignments were done using MODELLER v.6.2. ${ }^{58}$

\section{Hormone-receptor interaction studies}

Titration studies of ${ }^{15}$ Nlabeled hPRL with unlabeled hPRLR were performed at $298 \mathrm{~K}$. Two samples were prepared: (A) $40 \mu \mathrm{M}$ hPRL, $2 \mathrm{mM} \mathrm{NH} \mathrm{HCO}_{3}, 10 \%{ }^{2} \mathrm{H}_{2} \mathrm{O}$ (pH 8.0) (1:0); and (B) $140 \mu \mathrm{M}$ hPRLR, $40 \mu \mathrm{M}$ hPRL, $2 \mathrm{mM}$ $\mathrm{NH}_{4} \mathrm{HCO}_{3}, 10 \%{ }^{2} \mathrm{H}_{2} \mathrm{O}(\mathrm{pH}$ 8.0) (1:3.5). Sample (B) was added to sample (A) in aliquots resulting in NMR samples with the following molecular ratios: 1:0-1:0.5-1: 1-1:1.4:-1:1.75-1:3.5 ([ $\left.\left.{ }^{15} \mathrm{~N}\right] \mathrm{h} P R L: h P R L R-E C D\right)$ at a constant concentration of $40 \mu \mathrm{M}$ hPRL. ${ }^{15} \mathrm{~N},{ }^{1} \mathrm{H}$-TROSY-HSQC spectra were recorded on each sample. Assignments of $\left[{ }^{15} \mathrm{~N}\right] \mathrm{hPRL}$ at $298 \mathrm{~K}$ were obtained by lowering the temperature from $310 \mathrm{~K}$ in steps of $5 \mathrm{~K}$ and recording $\mathrm{H},{ }^{15} \mathrm{~N}-\mathrm{HSQC}$ spectra at each temperature. Native PAGE and SDS-PAGE were run on samples extracted from the NMR samples at the different ratios of hormone and receptor, including samples of unbound receptor. Analytical gel filtration experiments of a set of samples representing various ratios of hPRL:hPRLR were run on Superdex 75 in $25 \mathrm{mM}$ Tris- $\mathrm{HCl}$ (pH 8.0), $50 \mathrm{mM} \mathrm{NaCl}$ at room temperature. Protein concentrations varied between runs and were typically in the micromolar range. The column was calibrated using standard markers, blue dextran, and acetone, and the apparent partition coefficient, $K_{\mathrm{AV}}$, was calculated for all peaks.

\section{Data base deposits}

Atomic coordinates and experimental NMR restraints of human PRL have been deposited in the Protein Data Bank, Research Collaboratory for Structural Bioinformatics, Rutgers University, New Brunswick, NJ† under the accession code 1RW5. Chemical shift assignments for human PRL at $\mathrm{pH} 8.0$ have been deposited in BioMagResBank $\ddagger$ with the entry number 6643 .

\section{Acknowledgements}

Signe A. Sjørup and Gitte Knudsen are thanked for skilled technical assistance and Kirstine Steffensen for initial purification work on the receptor. We thank Dr Ingrid Struman for valuable discussions. The Danish Natural Science Councils (BBK) supported this work, which is a contribution from the SbiN-Lab supported by the John and Birthe Meyer Foundation.

\section{References}

1. Bole-Feysot, C., Goffin, V., Edery, M., Binart, N. \& Kelly, P. A. (1998). Prolactin (PRL) and its receptor: actions, signal transduction pathways and phenotypes observed in PRL receptor knockout mice. Endocr. Rev. 19, 225-268.

2. Sivaprasad, U., Canfield, J. M. \& Brooks, C. L. (2004). Mechanism for ordered receptor binding by human prolactin. Biochemistry, 43, 13755-13765.

$\dagger$ http://www.rcsb.org/

$\ddagger$ http://www.bmrb.wisc.edu/ 
3. Gertler, A. \& Djiane, J. (2002). Mechanism of ruminant placental lactogen action: molecular and in vivo studies. Mol. Genet. Metab. 75, 189-201.

4. Cunningham, B. C. \& Wells, J. A. (1989). Highresolution epitope mapping of hGH-receptor interactions by alanine-scanning mutagenesis. Science, 244, 1081-1085.

5. Goffin, V., Norman, M. \& Martial, J. A. (1992). Alanine-scanning mutagenesis of human prolactin: importance of the 58-74 region for bioactivity. Mol. Endocrinol. 6, 1381-1392.

6. Kinet, S., Goffin, V., Mainfroid, V. \& Martial, J. A. (1996). Characterization of lactogen receptor-binding site 1 of human prolactin. J. Biol. Chem. 271, 14353-14360.

7. Somers, W., Ultsch, M., de Vos, A. M. \& Kossiakoff, A. A. (1994). The X-ray structure of a growth hormoneprolactin receptor complex. Nature, 372, 478-481.

8. Cunningham, B. C. \& Wells, J. A. (1991). Rational design of receptor-specific variants of human growth hormone. Proc. Natl Acad. Sci. USA, 88, 3407-3411.

9. Luck, D. N., Huyer, M., Gout, P. W., Beer, C. T. \& Smith, M. (1991). Single amino acid substitutions in recombinant bovine prolactin that markedly reduce its mitogenic activity in $\mathrm{Nb} 2$ cell cultures. Mol. Endocrinol. 5, 1880-1886.

10. Bernichtein, S., Kayser, C., Dillner, K., Moulin, S., Kopchick, J. J., Martial, J. A. et al. (2003). Development of pure prolactin receptor antagonists. J. Biol. Chem. 278, 35988-35999.

11. Goffin, V., Bernichtein, S., Kayser, C. \& Kelly, P. A. (2003). Development of new prolactin analogs acting as pure prolactin receptor antagonists. Pituitary, 6, 89-95.

12. Bernichtein, S., Kinet, S., Jeay, S., Llovera, M., Madern, D., Martial, J. A. et al. (2001). S179D-human PRL, a pseudophosphorylated human PRL analog, is an agonist and not an antagonist. Endocrinology, 142, 3950-3963.

13. Ferrara, N., Clapp, C. \& Weiner, R. (1991). The 16K fragment of prolactin specifically inhibits basal or fibroblast growth factor stimulated growth of capillary endothelial cells. Endocrinology, 129, 896-900.

14. Clapp, C., Martial, J. A., Guzman, R. C., RentierDelrue, F. \& Weiner, R. I. (1993). The 16-kilodalton $\mathrm{N}$-terminal fragment of human prolactin is a potent inhibitor of angiogenesis. Endocrinology, 133, 1292-1299.

15. Bentzien, F., Struman, I., Martini, J. F., Martial, J. \& Weiner, R. (2001). Expression of the antiangiogenic factor 16K hPRL in human HCT116 colon cancer cells inhibits tumor growth in $\operatorname{Rag} 1(-/-)$ mice. Cancer Res. 61, 7356-7362.

16. Rycyzyn, M. A. \& Clevenger, C. V. (2002). The intranuclear prolactin/cyclophilin B complex as a transcriptional inducer. Proc. Natl Acad. Sci. USA, 99, 6790-6795.

17. Rycyzyn, M. A., Reilly, S. C., O'Malley, K. \& Clevenger, C. V. (2000). Role of cyclophilin B in prolactin signal transduction and nuclear retrotranslocation. Mol. Endocrinol. 14, 1175-1186.

18. Carter, P., Andersen, C. A. \& Rost, B. (2003). DSSPcont: continuous secondary structure assignments for proteins. Nucl. Acids Res. 31, 3293-3295.

19. Gertler, A., Grosclaude, J., Strasburger, C. J., Nir, S. \& Djiane, J. (1996). Real-time kinetic measurements of the interactions between lactogenic hormones and prolactin-receptor extracellular domains from several species support the model of hormone-induced transient receptor dimerization. J. Biol. Chem. 271, 24482-24491.

20. Keeler, C., Dannies, P. S. \& Hodsdon, M. E. (2003). The tertiary structure and backbone dynamics of human prolactin. J. Mol. Biol. 328, 1105-1121.

21. Sippl, M. J. (1993). Recognition of errors in threedimensional structures of proteins. Proteins: Struct. Funct. Genet. 17, 355-362.

22. Hooft, R. W., Vriend, G., Sander, C. \& Abola, E. E. (1996). Errors in protein structures. Nature, 381, 272.

23. Cornell, W. D., Cieplak, P., Bayly, C. I., Gould, I. R., Merz, K. M., Ferguson, D. M. et al. (1995). A 2Nd generation force-field for the simulation of proteins. Nucleic-acids, and organic-molecules. J. Am. Chem. Soc. 117, 5179-5197.

24. Cornell, W. D., Cieplak, P., Bayly, C. I., Gould, I. R., Merz, K. M., Ferguson, D. M. et al. (1996). A second generation force field for the simulation of proteins, nucleic acids, and organic molecules (vol 117, pg 5179, 1995). J. Am. Chem. Soc. 118, 2309.

25. Elkins, P. A., Christinger, H. W., Sandowski, Y., Sakal, E., Gertler, A., de Vos, A. M. \& Kossiakoff, A. A. (2000). Ternary complex between placental lactogen and the extracellular domain of the prolactin receptor. Nature Struct. Biol. 7, 808-815.

26. Ultsch, M. H., Somers, W., Kossiakoff, A. A. \& de Vos, A. M. (1994). The crystal structure of affinity-matured human growth hormone at $2 \AA$ resolution. J. Mol. Biol. 236, 286-299.

27. Clackson, T., Ultsch, M. H., Wells, J. A. \& de Vos, A. M. (1998). Structural and functional analysis of the 1:1 growth hormone:receptor complex reveals the molecular basis for receptor affinity. J. Mol. Biol. 277, 1111-1128.

28. de Vos, A. M., Ultsch, M. \& Kossiakoff, A. A. (1992). Human growth hormone and extracellular domain of its receptor: crystal structure of the complex. Science, 255, 306-312.

29. Goffin, V., Struman, I., Mainfroid, V., Kinet, S. \& Martial, J. A. (1994). Evidence for a second receptor binding site on human prolactin. J. Biol. Chem. 269, 32598-32606.

30. Cunningham, B. C., Henner, D. J. \& Wells, J. A. (1990). Engineering human prolactin to bind to the human growth hormone receptor. Science, 247, 1461-1465.

31. Rouzic, P. L., Sandra, O., Grosclaude, J., RentierDelrue, F., Jolois, O., Tujague, M. et al. (2001). Evidence of rainbow trout prolactin interaction with its receptor through unstable homodimerisation. Mol. Cell Endocrinol. 172, 105-113.

32. Tchelet, A., Staten, N. R., Creely, D. P., Krivi, G. G. \& Gertler, A. (1995). Extracellular domain of prolactin receptor from bovine mammary gland: expression in Escherichia coli, purification and characterization of its interaction with lactogenic hormones. J. Endocrinol. 144, 393-403.

33. Biener, E., Martin, C., Daniel, N., Frank, S. J., Centonze, V. E., Herman, B. et al. (2003). Ovine placental lactogen-induced heterodimerization of ovine growth hormone and prolactin receptors in living cells is demonstrated by fluorescence resonance energy transfer microscopy and leads to prolonged phosphorylation of signal transducer and activator of transcription (STAT)1 and STAT3. Endocrinology, 144, 3532-3540.

34. Sandowski, Y., Nagano, M., Bignon, C., Djiane, J., Kelly, P. A. \& Gertler, A. (1995). Preparation and 
characterization of recombinant prolactin receptor extracellular domain from rat. Mol. Cell Endocrinol. 115, 1-11.

35. Clackson, T. \& Wells, J. A. (1995). A hot spot of binding energy in a hormone-receptor interface. Science, 267, 383-386.

36. Luck, D. N., Gout, P. W., Kelsay, K., Atkinson, T., Beer, C. T. \& Smith, M. (1990). Recombinant methionyl bovine prolactin: loss of bioactivity after single amino acid deletions from putative helical regions. Mol. Endocrinol. 4, 1011-1016.

37. Sun, Z., Li, P. S., Dannies, P. S. \& Lee, J. C. (1996). Properties of human prolactin (PRL) and H27A-PRL, a mutant that does not bind $\mathrm{Zn}^{2+}$. Mol. Endocrinol. 10, 265-271.

38. Goffin, V., Kinet, S., Ferrag, F., Binart, N., Martial, J. A. \& Kelly, P. A. (1996). Antagonistic properties of human prolactin analogs that show paradoxical agonistic activity in the $\mathrm{Nb} 2$ bioassay. J. Biol. Chem. 271, 16573-16579.

39. Goffin, V., Martial, J. A. \& Summers, N. L. (1995). Use of a model to understand prolactin and growth hormone specificities. Protein Eng. 8, 1215-1231.

40. Goffin, V., Shiverick, K. T., Kelly, P. A. \& Martial, J. A. (1996). Sequence-function relationships within the expanding family of prolactin, growth hormone, placental lactogen, and related proteins in mammals. Endocr. Rev. 17, 385-410.

41. Bernat, B., Pal, G., Sun, M. \& Kossiakoff, A. A. (2003). Determination of the energetics governing the regulatory step in growth hormone-induced receptor homodimerization. Proc. Natl Acad. Sci. USA, 100, 952-957.

42. Walsh, S. T., Jevitts, L. M., Sylvester, J. E. \& Kossiakoff, A. A. (2003). Site2 binding energetics of the regulatory step of growth hormone-induced receptor homodimerization. Protein Sci. 12, 1960-1970.

43. Bernichtein, S., Jomain, J. B., Kelly, P. A. \& Goffin, V. (2003). The N-terminus of human prolactin modulates its biological properties. Mol. Cell Endocrinol. 208, 11-21.

44. Morin, A., Picart, R. \& Tixier-Vidal, A. (1996). Effects of the N-terminal cysteine mutation on prolactin expression and secretion in transfected cells. Mol. Cell Endocrinol. 117, 59-73.

45. Peterson, F. C. \& Brooks, C. L. (1997). Identification of a motif associated with the lactogenic actions of human growth hormone. J. Biol. Chem. 272, 21444-21448.

46. Peterson, F. C. \& Brooks, C. L. (2004). Different elements of mini-helix 1 are required for human growth hormone or prolactin action via the prolactin receptor. Protein Eng. Des. Sel. 17, 417-424.
47. Duda, K. M. \& Brooks, C. L. (2003). Differential effects of zinc on functionally distinct human growth hormone mutations. Protein Eng, 16, 531-534.

48. Duda, K. M. \& Brooks, C. L. (1999). Human growth hormone site 2 lactogenic activity requires a distant tyrosine164. FEBS Letters, 449, 120-124.

49. Kasimova, M. R., Kristensen, S. M., Howe, P. W., Christensen, T., Matthiesen, F., Petersen, J. et al. (2002). NMR studies of the backbone flexibility and structure of human growth hormone: a comparison of high and low pH conformations. J. Mol. Biol. 318, 679-695.

50. Paris, N., Rentier-Delrue, F., Defontaine, A., Goffin, V., Lebrun, J. J., Mercier, L. \& Martial, J. A. (1990). Bacterial production and purification of recombinant human prolactin. Biotechnol. Appl. Biochem. 12, 436-449.

51. Lerche, M. H., Meissner, A., Poulsen, F. M. \& Sorensen, O. W. (1999). Pulse sequences for measurement of one-bond N-15-H-1 coupling constants in the protein backbone. J. Magn. Reson. 140, 259-263.

52. Delaglio, F., Grzesiek, S., Vuister, G. W., Zhu, G., Pfeifer, J. \& Bax, A. (1995). NMRPipe: a multidimensional spectral processing system based on UNIX pipes. J. Biomol. NMR, 6, 277-293.

53. Kjær, M., Andersen, K. V. \& Poulsen, F. M. (1994). Automated and semiautomated analysis of homoand heteronuclear multidimensional nuclear magnetic resonance spectra of proteins: the program Pronto. Methods Enzymol. 239, 288-307.

54. Herrmann, T., Guntert, P. \& Wuthrich, K. (2002). Protein NMR structure determination with automated NOE assignment using the new software CANDID and the torsion angle dynamics algorithm DYANA. J. Mol. Biol. 319, 209-227.

55. Schwieters, C. D., Kuszewski, J. J., Tjandra, N. \& Clore, G. M. (2003). The Xplor-NIH NMR molecular structure determination package. J. Magn. Reson. 160, 65-73.

56. Kuszewski, J., Gronenborn, A. M. \& Clore, G. M. (1997). Improvements and extensions in the conformational database potential for the refinement of NMR and X-ray structures of proteins and nucleic acids. J. Magn. Reson. 125, 171-177.

57. Koradi, R., Billeter, M. \& Wuthrich, K. (1996). MOLMOL: a program for display and analysis of macromolecular structures. J. Mol. Graph. 14, 51-55.

58. Sali, A. \& Blundell, T. L. (1990). Definition of general topological equivalence in protein structures. A procedure involving comparison of properties and relationships through simulated annealing and dynamic programming. J. Mol. Biol. 212, 403-428.

Edited by M. F. Summers

(Received 30 March 2005; received in revised form 16 June 2005; accepted 17 June 2005) Available online 5 July 2005 